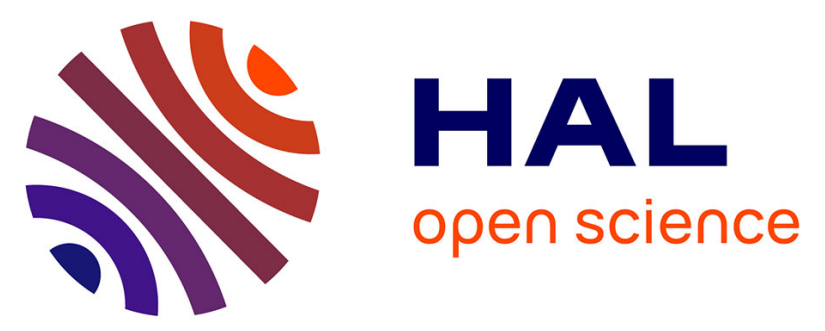

\title{
Borohydride-functionalized polydopamine-coated open cell polyurethane foam as a reusable soft structured material for reduction reactions: application to the removal of a dye
}

Louis Lefebvre, Julien Kelber, Xiyu Mao, Florian Ponzio, Géraldine Agusti, Cécile Vigier-Carrière, Vincent Ball, Loïc Jierry, Vincent Ritleng, David Edouard

\section{- To cite this version:}

Louis Lefebvre, Julien Kelber, Xiyu Mao, Florian Ponzio, Géraldine Agusti, et al.. Borohydridefunctionalized polydopamine-coated open cell polyurethane foam as a reusable soft structured material for reduction reactions: application to the removal of a dye. Environmental Progress \& Sustainable Energy, 2018, 38 (2), pp.329-335. 10.1002/ep.12944 . hal-01896113

\author{
HAL Id: hal-01896113 \\ https://hal.science/hal-01896113
}

Submitted on 17 Dec 2021

HAL is a multi-disciplinary open access archive for the deposit and dissemination of scientific research documents, whether they are published or not. The documents may come from teaching and research institutions in France or abroad, or from public or private research centers.
L'archive ouverte pluridisciplinaire HAL, est destinée au dépôt et à la diffusion de documents scientifiques de niveau recherche, publiés ou non, émanant des établissements d'enseignement et de recherche français ou étrangers, des laboratoires publics ou privés. 
Borohydride-functionalized polydopamine-coated open cell polyurethane foam as a reusable soft structured material for reduction reactions: application to the removal of a dye

Louis Lefebvre, ${ }^{\mathrm{a}}$ Julien Kelber, ${ }^{\mathrm{b}}$ Xiyu Mao, ${ }^{\mathrm{b}}$ Florian Ponzio, ${ }^{\mathrm{b}}$ Géraldine Agusti, ${ }^{\mathrm{a}}$ Cécile VigierCarrière, ${ }^{\mathrm{b}}$ Vincent Ball, ${ }^{\mathrm{c}}$ Loïc Jierry, ${ }^{* \mathrm{~b}}$ Vincent Ritleng*de and David Edouard*a

${ }^{a}$ Univ Lyon, Université Claude Bernard Lyon 1, Laboratoire d'Automatique et de Génie des Procédés, UMR CNRS 5007, 43 boulevard du 11 novembre 1918, F-69100 Villeurbanne, France.

${ }^{\text {b }}$ CNRS, Institut Charles Sadron UPR 022, 23 rue du Loess, F-67034 Strasbourg, France.

${ }^{\text {c } U n i v e r s i t e ́ ~ d e ~ S t r a s b o u r g, ~ I N S E R M ~ U 1121, ~} 11$ rue Humann, F-67000 Strasbourg, France.

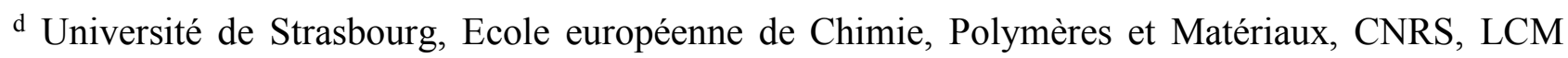
UMR 7509, Equipe de Chimie Organométallique Appliquée, 25 rue Becquerel, F-67087 Strasbourg, France.

${ }^{\mathrm{e}}$ Institut Universitaire de France, 1 rue Descartes, F-75005 Paris, France.

* Corresponding authors. E-mail addresses: loic.jierry@ics-cnrs.unistra.fr (L. Jierry), vritleng@,unistra.fr (V. Ritleng), david.edouard@,univ-lyon1.fr (D. Edouard) 
Open cell polyurethane foams coated with mussel-inspired polydopamine can be used as support for borohydride anions through their complexation by the catechol groups of the polydopamine layer. This strong interaction prevents borohydride hydrolysis and oxidation, and based on the redox mediator properties of polydopamine, the so-functionalized polydopamine-coated open cell polyurethane foams can act as efficient and reusable soft structured materials for the reduction of methylene blue in aqueous solution without additional sodium borohydride $\left(\mathrm{NaBH}_{4}\right)$. Very low amounts of released boron sub-products and very small potential of hydrogen (pH) increase are observed in comparison to previous processes using dissolved $\mathrm{NaBH}_{4}$. This considerably reduces the environmental impact of the reducing structured material on the treated wastewater compared to the latter.

Keywords: wastewater treatment, methylene blue, surface science

\section{INTRODUCTION}

The huge production of industrial dyes all over the world (700 $000 \mathrm{t} / \mathrm{year}$ ) and their use for textile applications are responsible of some of the main water contaminants [1]. Based on nitro- and amino-aromatic derivatives, some of these compounds are highly toxic for human health and the natural environment $[2,3]$. Over the last decades, many water decontamination processes have been developed. Among them, adsorption systems that use activated charcoal have shown their efficiency but require the frequent renewal of the filter cartridge [2,4,5]. Recent advances in nanotechnologies have allowed the design of efficient photo-catalytic systems that can decompose organic contaminants into harmless end products [6-8]. However, the implementation of ultraviolet (UV) lamps into industrial depollution systems is not suitable because of the high-energy cost that would be required to treat large volumes of wastewater. Alternatively, metallic nanoparticles that use sodium borohydride $\left(\mathrm{NaBH}_{4}\right)$ instead of UV lamps as an electron provider have been reported [9-15]. In this approach, the nanocomposite relays electrons from $\mathrm{NaBH}_{4}$ in an efficient way that leads to the degradation of dyes into non-toxic products. The main problem here is that 
$\mathrm{NaBH}_{4}$ is sensitive to water hydrolysis and therefore must be used in large excess. Thus, even though the concentration of dyes to be reduced in wastewater is usually low, this causes an economic problem in addition to environmental issues as hydrolysis of $\mathrm{NaBH}_{4}$ produces oxidized boron ions and considerably increases the potential of hydrogen $(\mathrm{pH})$ of the treated water.

In order to develop concrete depollution systems that can be used for the decontamination of industrial wastewater, the following points must be taken into account: $(i)$ nanomaterial-based catalysts should be strongly immobilized on a support to avoid the release of nano-objects in the environment, ( $i i)$ the chosen support must display an open cell structure to allow the treatment of wastewater with a reasonable flow [16-20], and to make sense (iii), no further contamination caused by the depolluting process itself must be released in the treated water. Last but not least, the development of such decontamination tools must integrate the necessity to be built in an environmentally friendly fashion. In view of these requirements, a non-innocent flexible structured material that consists in a open cell polyurethane foam coated with mussel-inspired polydopamine (PDA@OCPUF) and fulfils all the above-mentioned requirements is reported here. The latter indeed acts both as a protective support and a redox-mediator of $\mathrm{NaBH}_{4}$ through complexation of the borohydride anions by the catechol groups of the polydopamine (PDA) layer. Thus, the so functionalized structured support ( $\mathrm{NaBH}_{4} @ \mathrm{PDA} @$ OCPUF) allows the reduction of methylene blue (MB) - which, among the variety of cationic or azo dyes typically reduced by $\mathrm{NaBH}_{4}$ in the presence of a redox mediator [9-15], was used as a model of dye contaminant - without addition of $\mathrm{NaBH}_{4}$ in the reaction medium.

Thanks to its well-known redox properties [21,22], PDA indeed (i) stabilizes the grafted borohydride ions against hydrolysis and oxidation, (ii) plays the role of a redox mediator, and (iii) contributes to the reducing ability of the system. Furthermore, thanks to its strong binding abilities [23], PDA only releases a very low amount of borohydride into the medium, and thus allows a good pH control. The preparation of the reactive soft structured material, $\mathrm{NaBH}_{4} @ \mathrm{PDA} @$ OCPUF, is 
described, as well as its reductive properties. The interaction of the borohydride salt with PDA is discussed.

\section{EXPERIMENTAL SECTION}

\section{Materials and methods}

Commercial compounds were used as received. Polyurethane open cells foams (Regicell 20) were received from FoamPartner. Their characteristics are as follows: mean strut size: $220 \mu \mathrm{m}$; mean window size: $779 \mu \mathrm{m}$; mean cell size: $2500 \mu \mathrm{m}$; density: 0.027-0.033, porosity: 0.94-0.97. Cubic samples of $8 \mathrm{~cm}^{3}(180 \mathrm{mg} \pm 20 \mathrm{mg})$ were used without prior treatment. Dopamine hydrochloride, (99\%, A11136), Tris base (99\%, A18494), and methylene blue (high purity, A18174) were purchased from Alfa Aesar. $\mathrm{NaBH}_{4}(\geq 98 \%, 452882)$, sodium periodate $\left(\mathrm{NaIO}_{4}\right)(\geq$ $99.9 \%, 311448)$, and benzaldehyde $(\geq 99 \%$, B1334) were purchased from Sigma-Aldrich. Water purified by Synergy ${ }^{\circledR}$ Water Purification System (Millipore) was used for the preparation of the aqueous solutions and washing procedures. Scanning electron microscopy (SEM) was performed with a Hitachi S800 FEG microscope at the "Centre Technologique des Microstructures" (CT $\mu$ ) of the University of Lyon I. Samples of $\mathrm{NaBH}_{4} @ \mathrm{PDA} @$ OCPUF were deposited on a flat steel holder, coated under vacuum by cathodic sputtering with platinum, and observed under an accelerating voltage of $15 \mathrm{kV}$. UV-visible measurements for the methylene blue reductions were performed with a Varian Cary 50 Probe spectrophotometer. High Pressure Liquid Chromatography (HPLC) (Agilent 1100; SUPELCOSIL ABZ+PLUS column, $3 \mu \mathrm{M}, 15 \mathrm{~cm} \times 4.6 \mathrm{~mm}$ (Sigma-Aldrich); isocratic eluent: $\mathrm{H}_{2} \mathrm{O}+0.1 \%$ TFA/acétonitrile $60 / 40$; rate $\left.1 \mathrm{~mL} \cdot \mathrm{min}^{-1}\right)$ coupled to $\mathrm{UV}$ detection $(250$ $\mathrm{nm}$ ) was used to follow the reduction of benzaldehyde to benzylic alcohol. Inductively coupled plasma-atomic emission spectrometry (ICP-AES) measurements were performed by the "Platefome Analytique" of the "Institut Pluridisciplinaire Hubert Curien" (CNRS, UMR 7178), Strasbourg, France. 


\section{Open cell polyurethane foam (OCPUF) coating with polydopamine (PDA)}

With $\mathrm{O}_{2}$ as oxidant:PDA-O $\mathrm{O}_{2} @ O C P U F$.PDA-O $\mathrm{O}_{2} @$ OCPUF foams were prepared according to the published procedure [24] with cubic samples of $c a .2 \times 2 \times 2 \mathrm{~cm}(180 \mathrm{mg} \pm 20 \mathrm{mg})$ of OCPUF. The resulting samples of PDA-O ${ }_{2} @$ OCPUF showed a mass increase of $c a .1 .5$ to $5 \mathrm{mg}$ compared to pristine OCPUF.

With $\mathrm{NaIO}_{4}$ as oxidant:PDA-NaIO${ }_{4} @ O C P U F$. The coating procedure was adapted from that published by V. Ball and collaborators [25]. Dopamine hydrochloride (180 $\mathrm{mg}$ ) was dissolved in a $50 \mathrm{mM}$ aqueous solution $(90 \mathrm{~mL})$ of sodium acetate containing sodium periodate as oxidant (dopamine/oxidant molar ratio of $1 / 2$ ) and buffered to $\mathrm{pH} 5$ with aqueous $\mathrm{HCl}(1 \mathrm{M})$. A cubic sample of OCPUF ca. $2 \times 2 \times 2 \mathrm{~cm}(180 \mathrm{mg} \pm 20 \mathrm{mg})$ was dipped in the stirred solution for $24 \mathrm{~h}$ at room temperature. The solution rapidly turned dark brown. The resulting material was then taken out of the solution, and dried overnight in an oven at $67^{\circ} \mathrm{C}$. After that, it was dipped again in vigorously stirred water $(70 \mathrm{~mL})$ for $10 \mathrm{~min}$, and air-dried. This washing procedure was repeated 5 times, and the dark brown PDA-NaIO $4 @$ OCPUF was finally dried for two hours in an oven at 67 ${ }^{\circ} \mathrm{C}$, and characterized by SEM. Various samples showed a mass increase of $\mathrm{ca} .10$ to $12 \mathrm{mg}$ compared to pristine OCPUF.

\section{Functionalization of PDA@OCPUF with sodium borohydride $\left(\mathrm{NaBH}_{4}\right)$}

General procedure. $\mathrm{NaBH}_{4}(567 \mathrm{mg}, 15.0 \mathrm{mmol})$ was dissolved in water $(150 \mathrm{~mL})$. A cubic sample of PDA-O ${ }_{2} @$ OCPUF or PDA-NaIO $@$ OCPUF $\left(8 \mathrm{~cm}^{3}\right)$ was dipped in the stirred solution for $10 \mathrm{~min}$ at room temperature. The resulting borohydride-functionalized foam was taken out of the solution and dipped in vigorously stirred water $(70 \mathrm{~mL})$ for $30 \mathrm{~min}$ and air-dried. $\mathrm{NaBH}_{4} @$ PDA-NaIO $4 @$ OCPUF was characterized by SEM, and the boron content of $\mathrm{NaBH}_{4} @$ PDA-O $2 @$ OCPUF and $\mathrm{NaBH}_{4} @ \mathrm{PDA}_{2} \mathrm{NaIO}_{4} @$ OCPUF samples was determined by ICPAES (Table S1). 
Regeneration of a "deactivated" NaBH ${ }_{4} @ P D A-N^{2} O_{4} @ O C P U F$ foam. $\mathrm{NaBH}_{4}(567$ mg, 15.0 mmol $)$ was dissolved in water $(150 \mathrm{~mL})$. A "deactivated" sample of $\mathrm{NaBH}_{4} @$ PDA$\mathrm{NaIO}_{4} @$ OCPUF $\left(8 \mathrm{~cm}^{3}\right)$ was dipped in the stirred solution for $10 \mathrm{~min}$ at $20{ }^{\circ} \mathrm{C}$. The resulting borohydride-re-functionalized foam was taken out of the solution and dipped in vigorously stirred water $(70 \mathrm{~mL})$ for $30 \mathrm{~min}$ and air-dried.

\section{Cyclic voltammetry}

Dopamine was dissolved in Tris buffer containing $\mathrm{NaBH}_{4}$ at $50 \mathrm{mM}$. Immediately after the dissolution of dopamine, the solution was subjected to a cyclic voltammetry (CV) scan between 0.6 and +1.0 versus the $\mathrm{Ag} / \mathrm{AgCl}$ reference electrode at a potential scan rate of $100 \mathrm{mV} \cdot \mathrm{s}^{-1}$. A control experiment was performed with a pure dopamine solution at the same concentration without added $\mathrm{NaBH}_{4}$. Note that the $\mathrm{pH}$ of the $\mathrm{NaBH}_{4}$ solution increased to about 10 after the dissolution and had to be readjusted to 8.50 before the dissolution of dopamine. These experiments were performed to investigate the interactions between $\mathrm{BH}_{4}{ }^{-}$and dopamine from an electrochemical point of view. The $\mathrm{CV}$ experiments were performed in a three-electrode configuration with an amorphous carbon working electrode (ref. CHI 104, CHI Instruments, Austin, TX), a $\mathrm{Ag} / \mathrm{AgCl}$ reference electrode (ref. CHI 111) and a Pt wire auxiliary electrode (CHI 115). The potential difference between the working and the reference electrode was applied with a CHI 604B potentiostat. The carbon-working electrode was polished with $\mathrm{SiC}$ paper and then with alumina slurries of 1 and 0.1 $\mu \mathrm{m}$ (from Escil, Chassieu, France) in diameter before intensive sonication in water baths. The surface state of the amorphous carbon electrode was checked by performing a CV scan between 0.6 and $+1.0 \mathrm{~V}$ versus $\mathrm{Ag} / \mathrm{AgCl}$ in the presence of Tris buffer containing $1 \mathrm{mM} \mathrm{K}{ }_{4} \mathrm{Fe}(\mathrm{CN})_{6}(\mathrm{ref}$. P9387, Sigma-Aldrich). The experiment was only continued if the oxidation peak potential and the reduction peak potential of $\mathrm{K}_{4} \mathrm{Fe}(\mathrm{CN})_{6}$ were separated by less than $80 \mathrm{mV}$, the theoretical value being of $59 \mathrm{mV}$ for a reversible one electron transfer process. 


\section{$\mathrm{NaBH}_{4} @ P D A @ O C P U F-m e d i a t e d$ reduction of benzaldehyde}

A PDA-O ${ }_{2} @$ OCPUF sample $\left(8 \mathrm{~cm}^{3}\right)$ was functionalized by reaction with $10 \mathrm{~mL}$ of a freshly prepared aqueous solution of $\mathrm{NaBH}_{4}\left(\mathrm{NaBH}_{4} 22 \mathrm{wt} . \%, \mathrm{NaOH} 22 \mathrm{wt} . \%\right)$ for 1 min, washed with deionized water $(10 \mathrm{~mL})$, and subsequently dried with compressed air. The resulting $\mathrm{NaBH}_{4} @ \mathrm{PDA}$ $\mathrm{O}_{2} @$ OCPUF material was then dipped in a vigorously stirred solution of benzaldehyde $(0.200 \mathrm{~mL}$, $1.97 \mathrm{mmol})$ in methanol $(50 \mathrm{~mL})$ at room temperature and the reaction was followed by HPLC. After $10 \mathrm{~min}$, the conversion was found to be complete and the yield of benzyl alcohol was $100 \%$.

\section{$\mathrm{NaBH}_{4} @$ PDA@OCPUF-mediated reduction of methylene blue (MB)}

In a typical experiment, an aqueous solution of $\mathrm{MB}\left(50 \mathrm{~mL}, 2.10^{-5} \mathrm{M}\right)$ was stirred at room temperature $(700 \mathrm{rpm})$ in the presence of a cubic sample $\left(8 \mathrm{~cm}^{3}\right)$ of $\mathrm{NaBH}_{4} @ \mathrm{PDA} \mathrm{O}_{2} @ \mathrm{OCPUF}$ or $\mathrm{NaBH}_{4} @ \mathrm{PDA}^{-\mathrm{NaIO}_{4} @ O C P U F .}$ The disappearance of $\mathrm{MB}$ was followed by measuring the decrease of its absorbance peak at $664 \mathrm{~nm}$ in the UV-visible spectra of the reaction solution as a function of the reaction time. The percentage of $\mathrm{MB}$ removed from the solution was calculated according to equation (1):

$$
\mathrm{R}(\%)=100 \times[1-(\mathrm{C}(t) / \mathrm{C}(0)]
$$

where $R$ is the removal percentage, $C(0)$ the initial concentration of $\mathrm{MB}$ in the solution, and $C(t)$ the concentration in the solution at time $t$.

During some experiments, the evolution of the $\mathrm{pH}$ of the MB solutions was concomitantly monitored with a Mettler Toledo SG23-FK2 pH-meter. Between two successive runs, the foam was taken out of the reaction medium, washed with water and re-dipped in a fresh solution of MB.

\section{RESULTS AND DISCUSSION}

\section{Preparation and characterization of $\mathrm{NaBH}_{4} @ P D A @ O C P U F$}

PDA is a biomimetic coating inspired from the mussel adhesion mechanism that can form on almost all kind of materials from a simple, short and green process [23]. The oxygen from the air, 
naturally present in water, oxidizes dopamine that provides indole derivatives that are able to couple together through aryl-aryl oxidative coupling, thus leading to polydopamine structure [26]. A balance between catechol groups and their oxidized form (i.e. o-quinone) are disseminated all over the surface, underlying the reductive power of PDA $[27,28]$. Recently, PDA was shown to play the role of redox mediator [29], thus allowing the use of soft structured materials such as PDA@OCPUF [24,29] for the efficient reduction of MB in the presence of a large excess of $\mathrm{NaBH}_{4}$ [31,32]. Although being thermodynamically favourable, the reduction of $\mathrm{MB}$ with $\mathrm{NaBH}_{4}$ is indeed kinetically restricted in the absence of a catalyst $[9,10,29]$.

The molecular mechanism of this catalysed reduction in the presence of PDA@OCPUF is not clear [31], but some borohydride ions were suspected to reduce the $o$-quinone groups of the PDA layer and then interact with the resulting catechols to lead to a $\mathrm{NaBH}_{4}$-functionalized PDA@OCPUF material. This suspected behaviour has been used to prepare borohydridefunctionalized materials ( $\mathrm{NaBH}_{4} @$ PDA@OCPUF) by simply dipping samples of PDA@OCPUF into a $0.1 \mathrm{M}$ aqueous solution of $\mathrm{NaBH}_{4}$ for $10 \mathrm{~min}$ (Fig. 1). Then a second dipping step was carried out for $30 \mathrm{~min}$ in vigorously stirred deionized water to remove any excess of $\mathrm{NaBH}_{4}$ eventually adsorbed onto PDA@OCPUF. Of note, the characteristic black colour of the PDA coating had turned brownish after the dipping step into $0.1 \mathrm{M} \mathrm{NaBH} 4$ solution (Fig. S1, Supporting Information). Finally, the foams were dried under a nitrogen flow and stored under air. This procedure was carried out on two kinds of PDA@OCPUF materials: PDA-O 2 OCPUF and PDA$\mathrm{NaIO}_{4} @$ OCPUF, which differ from each other by the nature of the oxidant used for the PDA coating (see Experimental Section), and thus by the thickness of the PDA coating; the stronger oxidant, $\mathrm{NaIO}_{4}$, typically yielding the thicker PDA layer [25]. The investigation of these two processes was carried out to get a better understanding of the role of the PDA coating in the reduction reaction of $\mathrm{MB}$. 


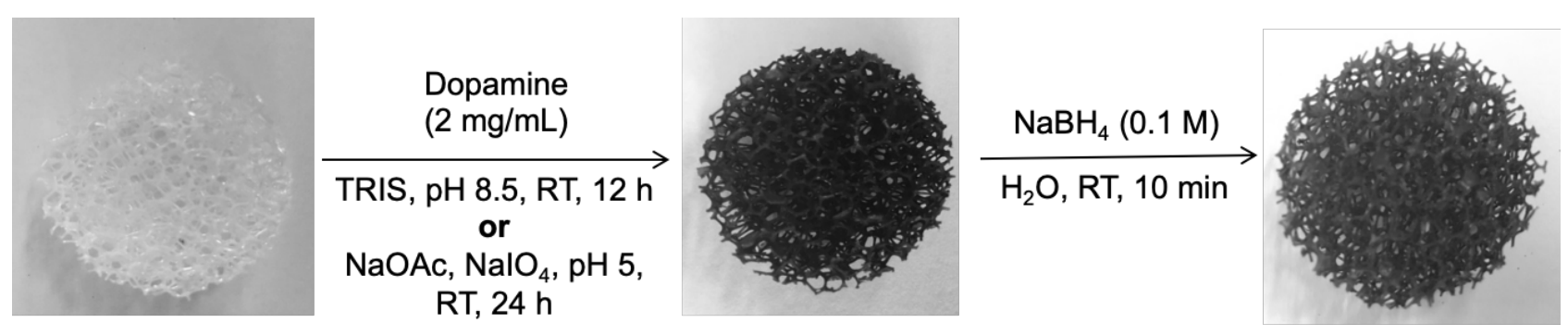

Figure 1. Two-step preparation of $\mathrm{NaBH}_{4} @ \mathrm{PDA} @$ OCPUF from OCPUF.

Simple weighing of several samples of OCPUF of $8 \mathrm{~cm}^{3}$ (ca. $180 \mathrm{mg}$ ) before and after the PDA coating revealed a mass difference of 1.5-5 mg for PDA- ${ }_{2} @$ OCPUF and of 10-12 mg for PDA$\mathrm{NaIO}_{4} @$ OCPUF in accordance with what was expected [25]. In contrast, inductively coupled plasma-atomic emission spectroscopy (ICP-AES) measurements on samples of $\mathrm{NaBH}_{4} @ \mathrm{PDA}$ $\mathrm{NaIO}_{4} @$ OCPUF and NaBH${ }_{4} @ \mathrm{PDA}_{2} \mathrm{O}_{2} @$ OCPUF revealed similar B contents of $22.4 \pm 1.3$ mg.kg-1 (i.e. $\left.2.07 \pm 0.12 \mu \mathrm{mol} . \mathrm{g}^{-1}\right)$. Scanning electron microscopy (SEM) images of PDA-NaIO ${ }_{4} @$ OCPUF and $\mathrm{NaBH}_{4} @ \mathrm{PDA}-\mathrm{NaIO}_{4} @$ OCPUF show aggregates of PDA, having micrometre size, randomly distributed on the whole surface of each foam, as previously reported (Fig. 2) [24]. These aggregates appear comprised of several layers on both types of foams. However, a closer comparison of PDA-NaIO $@$ @OCPUF and $\mathrm{NaBH}_{4} @ \mathrm{PDA} \mathrm{NaIO}_{4} @$ OCPUF images indicates that the morphology of PDA seems slightly impacted by the 10 min of dipping step into $\mathrm{NaBH}_{4}$ solution. Indeed, the top of the aggregates of $\mathrm{NaBH}_{4} @ \mathrm{PDA}-\mathrm{NaIO}_{4} @$ OCPUF appears rougher, which may indicate a partial degradation of the PDA layer during the dipping step. This would explain the observed lightening of the characteristic black colour of PDA (Fig. 1). Furthermore, no adsorbed macroscopic aggregates of $\mathrm{NaBH}_{4}$ into the PDA plates can be observed on $\mathrm{NaBH}_{4} @ \mathrm{PDA}$ $\mathrm{NaIO}_{4} @$ OCPUF (Fig. 2b), which tends to indicate that borohydride ions would interact at the molecular scale with PDA. 

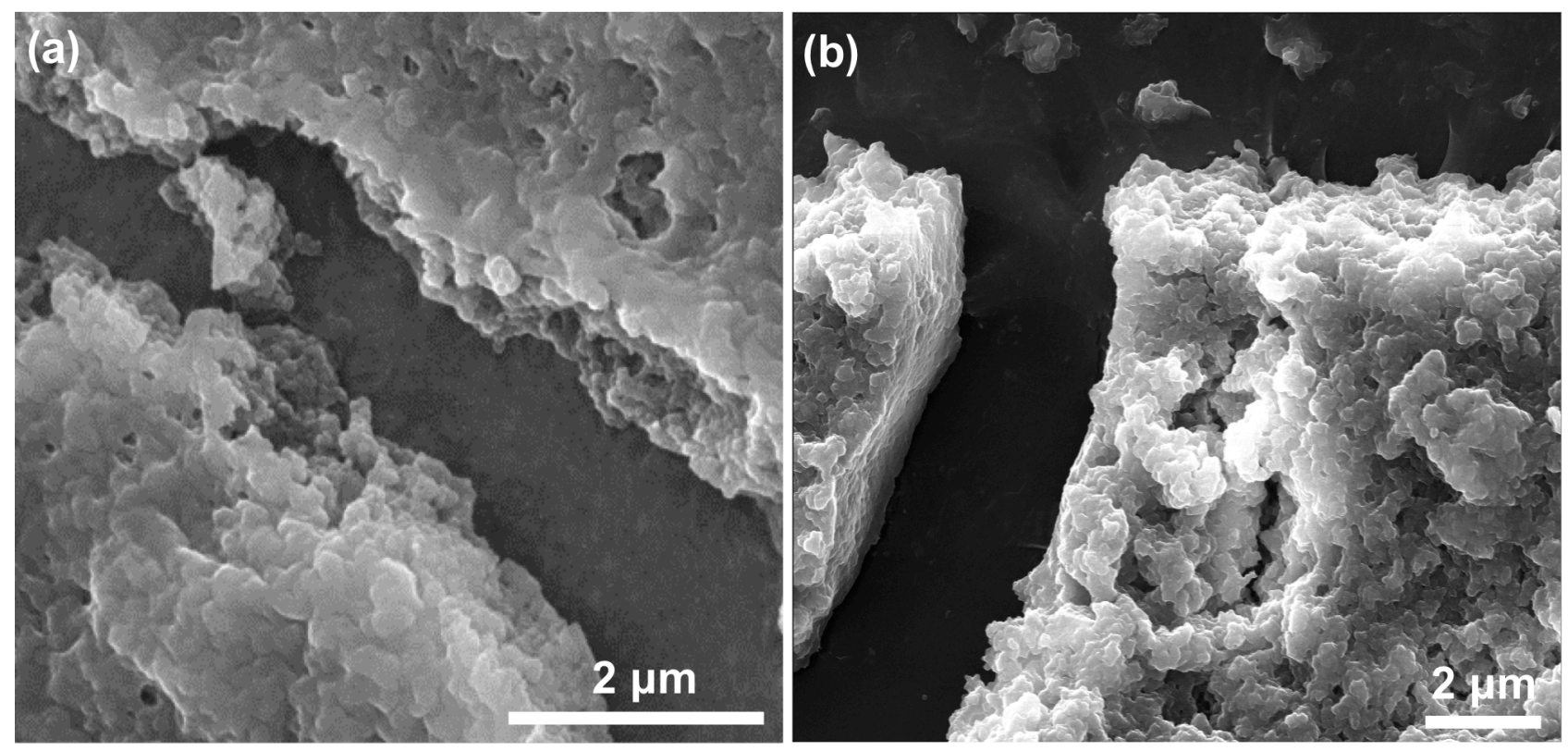

Figure 2. SEM images of PDA-NaIO 9 @OCPUF (a) and $\mathrm{NaBH}_{4} @ \mathrm{PDA} \mathrm{NaIO}_{4} @ O C P U F(b)$

To highlight the interaction between the catechols and the borohydrides, cyclic voltammetry (CV) experiments have been done on dopamine solutions $\left(2 \mathrm{mg} \cdot \mathrm{mL}^{-1}\right)$ to which $\mathrm{NaBH}_{4}$ had been added to reach a final concentration of $50 \mathrm{mM}$. The obtained cyclo-voltammogram was compared to that of dopamine without $\mathrm{NaBH}_{4}$ (Fig. 3). The oxidation peak of dopamine was shifted to anodic potentials by about $0.4 \mathrm{~V}$ in the presence of $\mathrm{NaBH}_{4}$, indicating that oxidation was less facile, and thus strongly suggesting the formation of complexes between the catechol moiety and borohydrides. This result is similar to those obtained by performing CV on catechol-boric acid mixtures [33]. In addition, these experiments were performed in the presence of Tris buffer at a $\mathrm{pH}$ of 8.5; conditions under which the dopamine solution rapidly turns brownish to its autoxidation in the presence of dissolved $\mathrm{O}_{2}$. However in the presence of $\mathrm{NaBH}_{4}$, even if the $\mathrm{pH}$ raised transiently above $10-$ which are conditions even more favourable to dopamine autoxidation - and was readjusted to 8.5, the dopamine solution remained transparent during hours, showing again that dopamine interacts strongly with $\mathrm{NaBH}_{4}$ and is protected against spontaneous oxidation. 


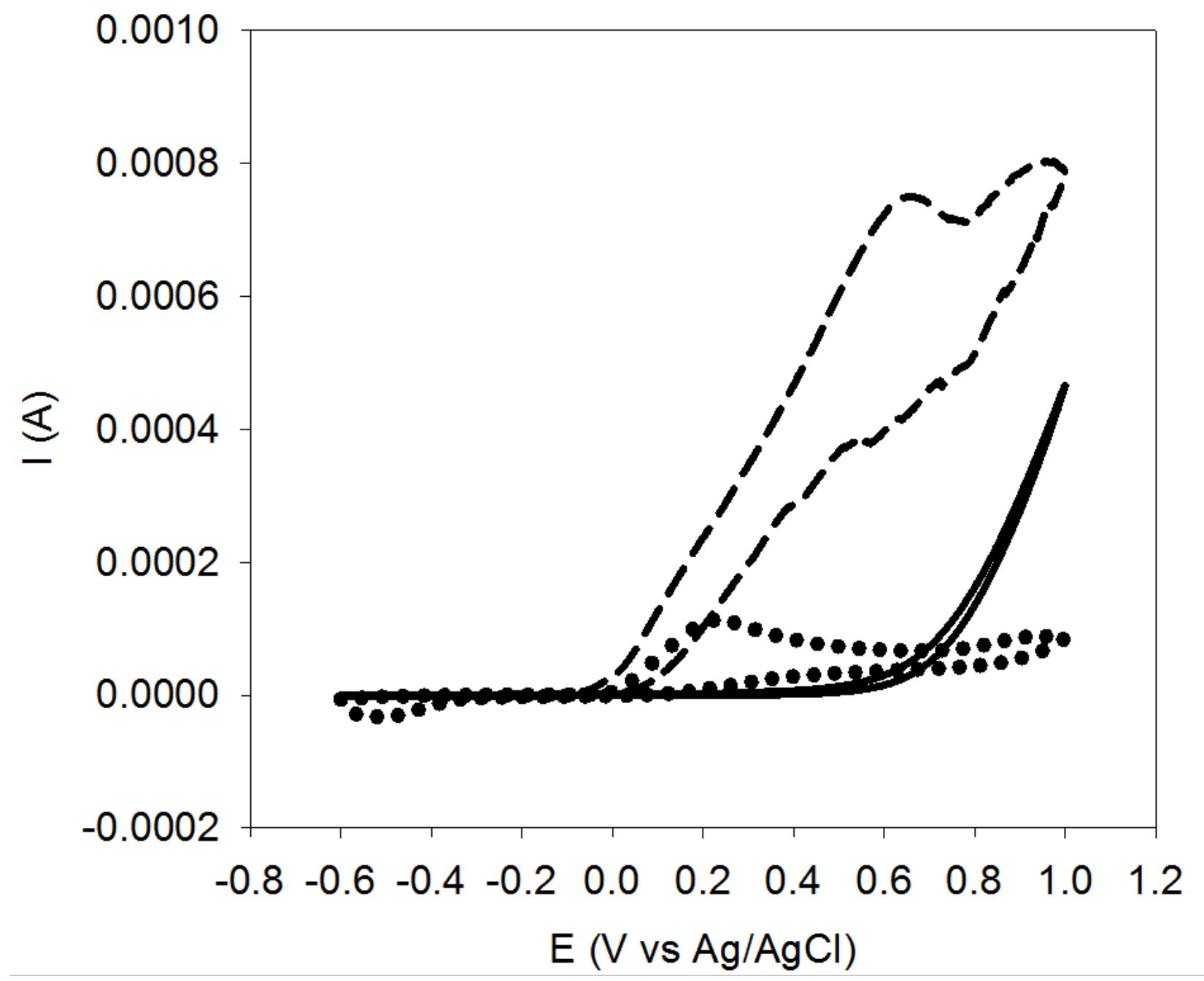

Figure 3. Cyclic voltammetry performed on a $\mathrm{NaBH}_{4}$ solution $(50 \mathrm{mM})$ (solid curve), a $\mathrm{NaBH}_{4}$ solution $(50 \mathrm{mM})$ containing dopamine $\left(2 \mathrm{mg} \cdot \mathrm{mL}^{-1}\right.$ or $\left.10.6 \mathrm{mM}\right)$ (dashed curve) and a dopamine solution ( $2 \mathrm{mg} \cdot \mathrm{mL}^{-1}$ or $10.6 \mathrm{mM}$ ) without added $\mathrm{NaBH}_{4}$ (dotted curve). The potential scan rate was of $100 \mathrm{mV} \cdot \mathrm{s}^{-1}$. All solutions were made from $50 \mathrm{mM}$ Tris buffer at $\mathrm{pH} 8.5$.

\section{Reduction of benzaldehyde}

The activity of the functionalized foam was first investigated for the reduction of benzaldehyde. When a cubic sample of $8 \mathrm{~cm}^{3}$ of $\mathrm{NaBH}_{4} @ \mathrm{PDA}_{2} @$ OCPUF was dipped into a $3.94 \times 10^{-2} \mathrm{M}$ solution of benzaldehyde in methanol $(50 \mathrm{~mL})$, the monitoring by HPLC coupled with UV detection showed a complete conversion in benzyl alcohol after 10 min of stirring at room temperature (Fig. 4), thus demonstrating the reducing ability of the borohydride-functionalized foam. 


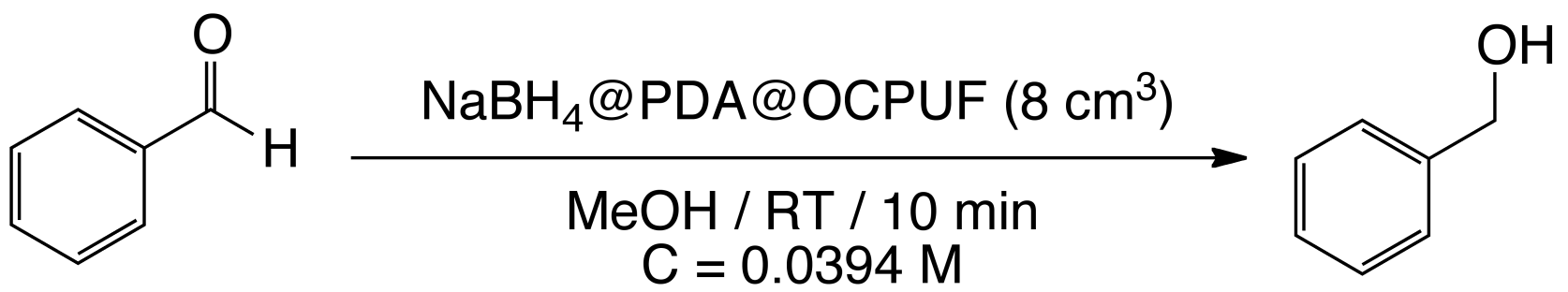

Figure 4. Reduction of benzaldehyde in benzyl alcohol by $\mathrm{NaBH}_{4} @ \mathrm{PDA}^{-\mathrm{O}_{2} @ O C P U F}$

\section{Removal of methylene blue}

The activity of the borohydride-functionalized foam was next evaluated for the reduction of MB in leuco-methylene in water. Experiments were conducted by simply immerging a sample of

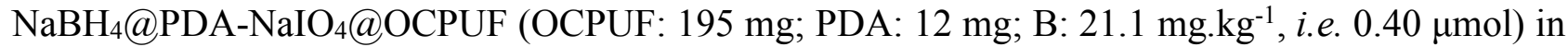
a stirred aqueous solution of $\mathrm{MB}\left(50 \mathrm{~mL}, 2 \times 10^{-5} \mathrm{M}, 1 \mu \mathrm{mol}\right)$ at room temperature. The reduction of MB was followed by the measure of the decrease of the absorbance peak at $664 \mathrm{~nm}$ in the UVvisible spectrum of the reaction medium as a function of time. After $25 \mathrm{~min}$, the functionalized foam was removed from the treated MB solution, rinsed with distilled water, and reused by reimmersion in a fresh solution of MB. Over $97 \%$ removal was observed after 25 min in the first run (Fig. 5a $-\mathrm{NaIO}_{4}$ Run 1), leading to a colourless solution (Fig. S2, Supporting information). Remarkably no deactivation was observed in the $2^{\text {nd }}$ and $3^{\text {rd }}$ runs, with discolouration ratios over 95\% in 25 min (Fig. 5a - $\mathrm{NaIO}_{4}$ Runs 2 and 3), and only a slight decrease in activity was observed in the $4^{\text {th }}$ and $5^{\text {th }}$ runs with degradation ratios of $c a .89$ and $87 \%$ after 25 min, respectively (Fig. 5a$\mathrm{NaIO}_{4}$ Runs 4 and 5). Even more remarkably, these results compare advantageously, both in terms of kinetics and efficiency, with the average activity observed for five consecutive runs with PDA@OCPUF (180 mg) in the presence of a large excess of $\mathrm{NaBH}_{4}(0.1 \mathrm{M})$; a fresh solution of $\mathrm{NaBH}_{4}$ being used at each run (Fig. 5a-PDA@OCPUF with $\mathrm{NaBH}_{4} 0.1 \mathrm{M}$ ) [31]. Furthermore, in the absence of $\mathrm{NaBH}_{4}$, only 11\% MB removal was observed after 25 min (Fig 5a. - PDA@OCPUF without $\mathrm{NaBH}_{4}$ ), which shows that PDA is unable to reduce $\mathrm{MB}$ efficiently by itself and that $\mathrm{MB}$ adsorption onto PDA is not predominant here. 
The influence of the amount of PDA coating was next examined by studying the activity of a sample of $\mathrm{NaBH}_{4} @$ PDA-O ${ }_{2} @$ OCPUF (OCPUF: 170 mg; PDA: 4.7 mg; B: 23.7 mg.kg-1 i.e. 0.38 $\mu \mathrm{mol})$ that shows a lower PDA content under similar conditions. About $97 \%$ and $90 \% \mathrm{MB}$ reduction were observed after $25 \mathrm{~min}$ in the two first runs, but the activity quickly decreased in the following runs (Fig. $5 \mathrm{~b}-\mathrm{O}_{2}$ Runs 1 to 5 ).

Considering ( $i$ ) that the amount of immobilized boron is similar on both types of NaBH 9 PDA@OCPUF $(0.39 \pm 0.01 \mu \mathrm{mol}),(i i)$ that the maximum possible amount of hydrides (ca. $1.56 \mu \mathrm{mol}$ if one considers that each $\mathrm{B}$ atom corresponds to a $\mathrm{BH}_{4}^{-}$anion) is too low for the amount of MB to be reduced in the five consecutive runs $(5 \mu \mathrm{mol})$, especially when one consider that these reductions are carried out in water, this clearly shows the importance of PDA in the redox process. Thus, in addition to playing the role of a redox mediator (or electro-catalyst) that allows the efficient reduction of MB by borohydrides [29,32], PDA presumably prevents the hydrolysis and oxidation of the immobilized borohydrides, and somehow participates to the reduction of MB: the reduced o-quinone functionalities (to catechols) that were generated during the $\mathrm{NaBH}_{4}$ functionalization serving as an additional source of electrons. This would explain that the thicker the PDA layer, the higher the reducing ability of the resulting $\mathrm{NaBH}_{4} @ \mathrm{PDA} @ O C P U F$ material. 

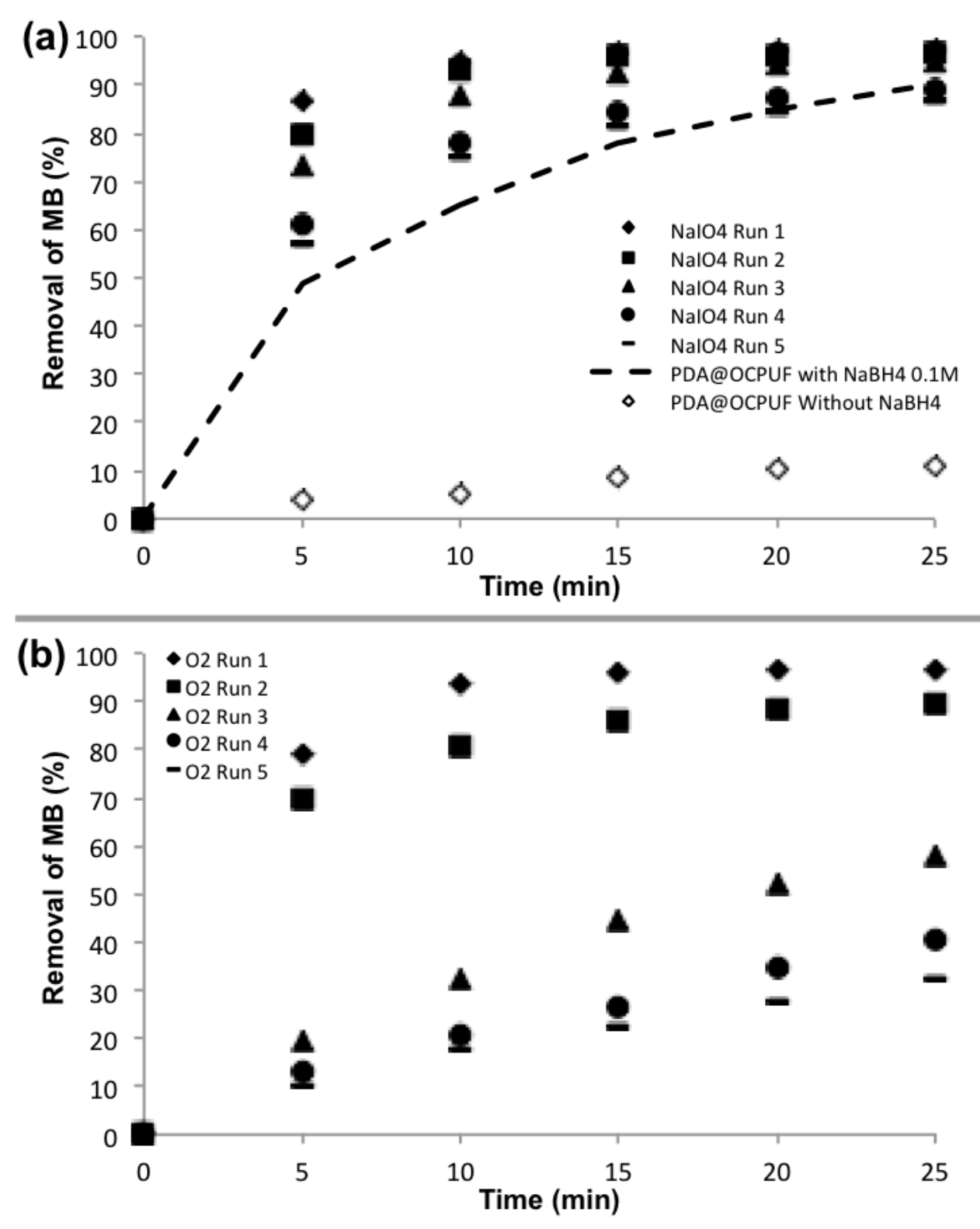

Figure 5. (a) Percentage of MB removal $\left(50 \mathrm{~mL}, 2 \times 10^{-5} \mathrm{M}, 1 \mu \mathrm{mol}\right)$ as a function of reaction time

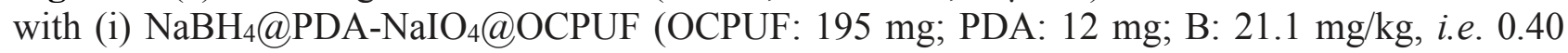
$\mu \mathrm{mol})$, runs 1 to 5, (ii) PDA@OCPUF with added $\mathrm{NaBH}_{4}$ in the medium $(0.1 \mathrm{M})$; average activity of 5 consecutive runs [31], and (iii) PDA@OCPUF in the absence of $\mathrm{NaBH}_{4}$ [31]. (b) Percentage of MB removal $\left(50 \mathrm{~mL}, 2 \times 10^{-5} \mathrm{M}, 1 \mu \mathrm{mol}\right)$ as a function of reaction time with $\mathrm{NaBH}_{4} @ \mathrm{PDA}$ O $@$ OCPUF (OCPUF: 170 mg; PDA: $4.7 \mathrm{mg}$; B: $23.7 \mathrm{mg} / \mathrm{kg}$, i.e. $0.38 \mu \mathrm{mol}$ ), runs 1 to 5.

The protecting ability of PDA was further confirmed by the behaviour of a $\mathrm{NaBH}_{4} @$ PDA$\mathrm{NaIO}_{4} @$ OCPUF material that was stored for one week in the air before use. Indeed, no significant difference was observed compared to a freshly prepared material (Fig. S3, Supporting information). 
As can be inferred from the lower B content of the foams after the five runs $\left(8 \pm 1 \mathrm{mg} \cdot \mathrm{kg}^{-1}\right.$, Table S1, Supporting information), some B leaching to the medium was however observed by ICPAES of the filtrates. This leaching, which may explain the progressive loss of activity of the borohydride-functionalized foams, varies from $4.4 \times 10^{-3} \mathrm{wt} . \%$ in the $1^{\text {st }}$ run to $8.0 \times 10^{-4} \mathrm{wt} . \%$ in the $5^{\text {th }}$ run with $\mathrm{NaBH}_{4} @ \mathrm{PDA} \mathrm{NaIO}_{4} @$ OCPUF and from $6.8 \times 10^{-3} \mathrm{wt} . \%$ in the first run to less than $6.0 \times 10^{-4}$ wt.\% in the $5^{\text {th }}$ run with $\mathrm{NaBH}_{4} @$ PDA-O ${ }_{2} @ O C P U F$. It thus remains very low when compared to the use of a $0.1 \mathrm{M}$ solution of $\mathrm{NaBH}_{4}(0.108 \mathrm{wt} . \% \mathrm{~B})$ to treat the same amount of $\mathrm{MB}$ with PDA@OCPUF [31], which considerably reduces the environmental impact of boron subproducts on the treated wastewater. Furthermore, the low borohydride release into the solutions has also positive consequences on the $\mathrm{pH}$ variation of the treated solutions. Whereas the $\mathrm{pH}$ of a $0.1 \mathrm{M}$ aqueous solution of $\mathrm{NaBH}_{4}$ rapidly reaches values $\geq 10$, the $\mathrm{pH}$ of the $\mathrm{MB}$ solutions treated with a

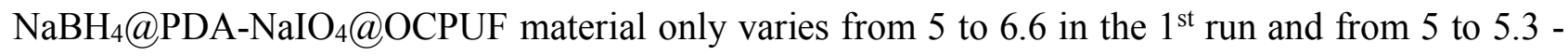
5.8 in the following runs (Fig. 6). A similar behaviour is observed with $\mathrm{NaBH}_{4} @ \mathrm{PDA} \mathrm{O}_{2} @ \mathrm{OCPUF}$ (Fig. S4, Supporting information).

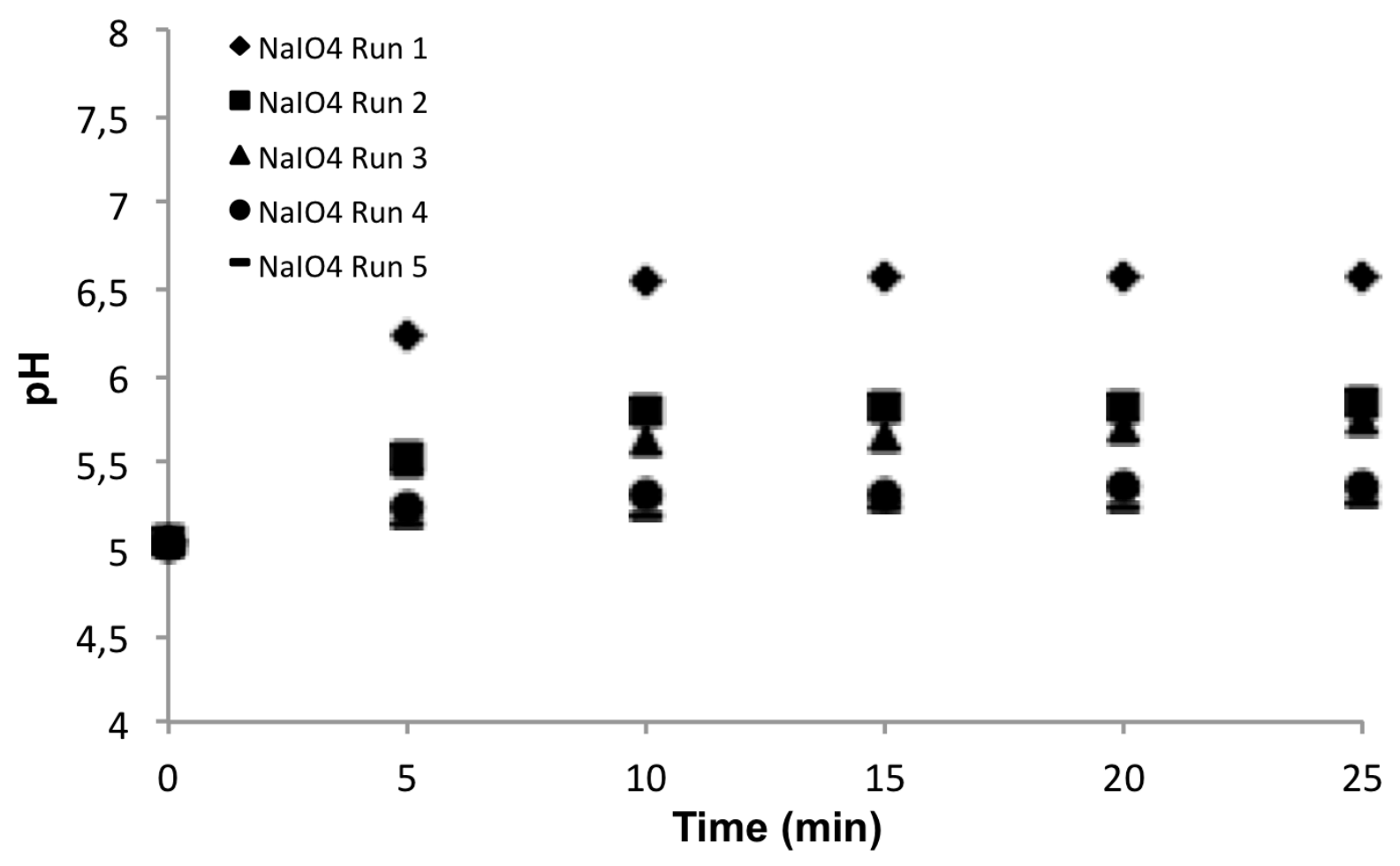


Figure 6. $\mathrm{pH}$ variation of the $\mathrm{MB}$ solutions treated with $\mathrm{NaBH}_{4} @ \mathrm{PDA}-\mathrm{NaIO}_{4} @$ OCPUF as a function of reaction time

Since the deactivation of the functionalized foam seems to be due to the leaching of borohydrides species, a used $\mathrm{NaBH}_{4} @ \mathrm{PDA} \mathrm{NaIO}_{4} @ \mathrm{OCPUF}$ material was re-functionalized (after 5 runs) by simple dipping in a fresh $0.1 \mathrm{M} \mathrm{NaBH}_{4}$ solution for $10 \mathrm{~min}$. The reducing activity of the thus re-functionalized foam was next examined under the same conditions as before. Satisfyingly, the first run of the $2^{\text {nd }}$ series led again to over $97 \%$ reduction of $\mathrm{MB}$ in $25 \mathrm{~min}$. However, in the following runs, the activity decreased a little more quickly than in the $1^{\text {st }}$ series (Fig. S5, Supporting information). This may due to the possible degradation of the PDA coating during the $\mathrm{NaBH}_{4}$ dipping treatment as suggested by the SEM images (Fig. 2). This problem may however be circumvented by using recently described PDA deposition processes that should lead to more chemically robust coatings [34,35].

\section{CONCLUSIONS}

In summary, an open cell polyurethane foam coated with mussel-inspired polydopamine has been used as both a redox mediator (or electro-catalyst) and a protective support for borohydride ions, neither PDA nor $\mathrm{BH}_{4}^{-}$being able to reduce $\mathrm{MB}$ efficiently by itself. The borohydrides have been shown by cyclic voltammetry to interact strongly with the catechol groups of polydopamine. This interaction provides protection from water hydrolysis and air oxidation to the borohydride anions, and the thicker the PDA layer, the better the stabilization; the excess catechols (compared to the classical balance of PDA between catechols and $o$-quinones) that were generated during the $\mathrm{NaBH}_{4}$-functionalization serving as an additional source of electrons. Thus, without addition of $\mathrm{NaBH}_{4}$ in solution, which allows important cost savings compared to decontamination processes using solutions of $\mathrm{NaBH}_{4}$, the functionalized support can quickly reduce MB (or benzaldehyde) and can be re-used at least three times without loss of its reductive property. In addition, the amount of released boron sub-products and the $\mathrm{pH}$ variations are much lower compared to processes using 
dissolved $\mathrm{NaBH}_{4}$, which considerably reduces the environmental impact of the current process on the treated wastewater compared to the latter. Finally, dipping of a deactivated foam into a fresh solution of $\mathrm{NaBH}_{4}$ partly regenerates its reductive property. Hence, $\mathrm{NaBH}_{4} @ \mathrm{PDA} @$ OCPUF appears as highly efficient, reusable, economically advantageous, and environmentally friendly.

Furthermore, it must also be pointed out that PDA@OCPUF is a soft structured material particularly well adapted to industrial applications because of its low cost, light weight, easiness to handle, elastic properties and most importantly here, because water can flow through at high speed with small pressure loss. This work should be useful for further development of decontamination systems of industrial wastewater.

\section{ACKNOWLEDGMENTS}

This research was supported by grants from the ANR (project "POLYCATPUF" ANR-16CE07-0030-01), the SATT Conectus Alsace, and the University of Lyon 1.

\section{LITERATURE CITED}

[1] Wu, Z., Zhong, H., Yuan, X., Wang, H., Wang, L., Chen, X., Zeng, G., Wu, Y. (2014). Adsorptive removal of methylene blue by rhamnolipid-functionalized graphene oxide from wastewater. Water Res., 67, 330-344.

[2] Rafatullah, M., Sulaiman, O., Hashim, R., Ahmad, A. (2010). Adsorption of methylene blue on low-cost adsorbents: A review. J. Hazard. Mater., 177, 70-80.

[3] Hu, L., Yang, F., Lu, W., Hao, Y., Yuan, H. (2013). Heterogeneous activation of oxone with CoMg/SBA-15 for the degradation of dye Rhodamine B in aqueous solution. Appl. Catal. B, 134-135, 7-18.

[4] Paulino, A.T., Guilherme, M.R., Reis, A.V., Campese, G.M., Muniz, E.C., Nozaki, J. (2006). Removal of methylene blue dye from an aqueous media using superabsorbent hydrogel supported on modified polysaccharide. J. Colloid Interface Sci., 301, 55-62. 
[5] Ali, I. (2012). New generation adsorbents for water treatment. Chem. Rev., 112, 5073-5091.

[6] Khan, M.M., Ansari, S.A., Amal, M.I., Lee, J., Cho, M.H. (2013). Highly visible light active $\mathrm{Ag} @ \mathrm{TiO}_{2}$ nanocomposites synthesized using an electrochemically active biofilm: a novel biogenic approach. Nanoscale, 5, 4427-4435.

[7] Thomas, J., Yoon, M. (2012). Facile synthesis of pure $\mathrm{TiO}_{2}(\mathrm{~B})$ nanofibers doped with gold nanoparticles and solar photocatalytic activities. Appl. Catal. B, 111-112, 502-508.

[8] Rauf, M.A., Ashraf, S. (2009). Fundamental principles and application of heterogeneous photocatalytic degradation of dyes in solution. Chem. Eng. J., 151, 10-18.

[9] Gupta, N., Singh, H.P., Sharma, R.K. (2011). Metal nanoparticles with high catalytic activity in degradation of methyl orange: an electron relay effect. J. Mol. Catal. A, 335, 248-252.

[10] Khan, M.M., Lee, J., Cho, M.H. (2014). Au@ $\mathrm{TiO}_{2}$ nanocomposites for the catalytic degradation of methyl orange and methylene blue: an electron relay effect. J. Ind. Eng. Chem., 20, 1584-1590.

[11] Ali, N., Awais, Kamal, T., Ul-Islam, M., Khan, A., Shah, S.J., Zada, A. (2018). Chitosancoated cotton cloth supported copper nanoparticles for toxic dye reduction. Int. J. Bio. Macromol., 111, 832-838.

[12] Zhou, X., Wan, J., Liu, Y., Liu, D., Wang, H., Lai, X., Zou, Y., Lin, G., Chen, J. (2017). Sizecontrolled silver nanoparticles confined in ordered mesoporous silica and their enhanced catalytic activities. Nano, 12, 1750104.

[13] Wang, N., Hu, Y., Zhang, Z. (2017). Sustainable catalytic properties of silver nanoparticles supported montmorillonite for highly efficient recyclable reduction of methylene blue. Appl. Clay Sci., 150, 47-55.

[14] Kohantorabi, M., Gholami, M.R. (2017). $\mathrm{M}_{\mathrm{x}} \mathrm{Ni}_{100-\mathrm{x}}(\mathrm{M}=\mathrm{Ag}$, and Co) nanoparticles supported on $\mathrm{CeO}_{2}$ nanorods derived from $\mathrm{Ce}$-metal organic frameworks as an effective catalyst for reduction of organic pollutants: Langmuir-Hinshelwood kinetics and mechanism. New J. Chem. 41, 10948-10958. 
[15] Mallikarjuna, K., Raju, B.D.P., Park, S., Kim, H. (2017). Synthesis and catalytic activity of alkylamine-capped ultra-small palladium nanoparticles for organic pollutant degradation. J. Cluster Sci. 28, 2833-2846.

[16] Bakker, J.J.W., Groendijk, W.J., de Lathouder, K.M., Kapteijn, F., Moulijn, J.A., Kreutzer, M.T., Wallin, S.A. (2007). Enhancement of catalyst performance using pressure pulses on macroporous structured catalysts. Ind. Eng. Chem. Res., 46, 8574-8583.

[17] Edouard, D., Lacroix, M., Pham Huu, C., Luck, F. (2008). Pressure drop modeling on SOLID foam: state of the art correlation. Chem. Eng. J., 144 299-311.

[18] Truong Huu, T., Lacroix, M., Pham Huu, C,. Schweich, D., Edouard, D. (2009). Towards a more realistic modeling of solid foam: use of the pentagonal dodecahdedron geometry. Chem. Eng. Sci., 64, 5131-5142.

[19] Richardson, J.T., Remue, D., Hung, J.-K. (2003). Properties of ceramic foam catalyst supports: mass and heat transfer. Appl. Catal. A, 250, 319-329.

[20] Giani, L., Groppi, G., Tronconi, E. (2005). Mass-transfer characterization of metallic foams as supports for structured catalysts. Ind. Eng. Chem. Res., 44, 4993-5002.

[21] Liu, Y., Ai, K., Lu, L. (2014). Polydopamine and its derivative materials: synthesis and promising applications in energy, environmental, and biomedical fields. Chem. Rev., 114, $5057-5115$.

[22] Kim, J.H., Lee, M., Park, C.B. (2014). Polydopamine as a biomimetic electron gate for artificial photosynthesis. Angew. Chem. Int. Ed., 53, 6364-6368.

[23] Lee, H., Dellatore, S.M., Miller, W.M., Messersmith, P.B. (2007). Mussel-Inspired Surface Chemistry for Multifunctional Coatings. Science, 318, 426-430.

[24] Pardieu, E., Chau, N.T.T., Dintzer, T., Romero, T., Favier, D., Roland, T., Edouard, D., Jierry, L., Ritleng, V. (2016). Polydopamine-coated open cell polyurethane foams as an inexpensive, flexible yet robust catalyst support: a proof of concept. Chem. Commun., 52, 4691-4693. 
[25] Ponzio, F., Barthès, J., Bour, J., Michel, M., Bertani, P., Hemmerlé, J., d'Ischia, M., Ball, V. (2016). Oxidant control of polydopamine surface chemistry in acids: a mechanism-based entry to superhydrophilic-superoleophobic coatings. Chem. Mater., 28, 4697-4705.

[26] Kang, X., Cai, W., Zhang, S., Cui, S. (2017). Revealing the formation mechanism of insoluble polydopamine by using a simplified model. Polym. Chem., 8, 860-864.

[27] Zangmeister, R.A., Morris, T.A., Tarlov, M.J. (2013). Characterization of polydopamine thin films deposited at short times by autoxidation of dopamine. Langmuir, 29, 8619-8628.

[28] Bernsmann, F., Ponche, A., Ringwald, C., Hemmerlé, J., Raya, J., Bechinger, B., Voegel, J.C., Schaaf, P., Ball, V. (2009). Characterization of dopamine-melanin growth on silicon oxide. J. Phys. Chem. C, 113, 8234-8242.

[29] Du, S., Liao, Z., Qin, Z., Zuo, F., Li, X. (2015). Polydopamine microparticles as redox mediators for catalytic reduction of methylene blue and rhodamine B. Catal. Commun., 72, 86-90.

[30] Edouard, D., Ritleng, V., Jierry, L., Chau Dalencon, N.T.T. (2016). Method for modifying the surface properties of elastomer cellular foams. WO 2016012689 A2.

[31] Lefebvre, L., Kelber, J., Jierry, L., Ritleng, V., Edouard, D. (2017). Polydopamine-coated open cell polyurethane foam as an efficient and easy-to-regenerate soft structured catalytic support (S2CS) for the reduction of dye. J. Environ. Chem. Eng., 5, 79-85.

[32] Edouard, D., Lefebvre, L., Jierry, L., Ritleng, V,. Kelber, J. (2018). Reduction kit, reducing composition and use of said kit and composition. WO 2018020146 A1.

[33] Rafiee, M., Nematollahi, D. (2008). Electrochemical study of catechol-boric acid complexes. Electrochim. Acta, 53, 2751-2756.

[34] Zhang, C., Ou, Y., Lei, W.-X., Wan, L.-S., Ji, J., Xu, Z.-K. (2016). CuSO $4 / \mathrm{H}_{2} \mathrm{O}_{2}$-induced rapid deposition of polydopamine coatings with high uniformity and enhanced stability. Angew. Chem. Int. Ed., 55, 3054-3057. 
[35] Yang, H.-C., Liao, K.-J., Huang, H., Wu, Q.-Y., Wan, L.-S., Xu, Z.-K. (2014). Musselinspired modification of a polymer membrane for ultra-high water permeability and oil-inwater emulsion separation. J. Mater. Chem. A, 2, 10225-10230. 